This item was submitted to Loughborough's Research Repository by the author.

Items in Figshare are protected by copyright, with all rights reserved, unless otherwise indicated.

\title{
Evidence for alternative exhaled elimination profiles of disinfection by- products and potential markers of airway responses to swimming in a chlorinated pool environment
}

\section{PLEASE CITE THE PUBLISHED VERSION}

https://doi.org/10.1111/ina.12630

\section{PUBLISHER}

Wiley

\section{VERSION}

AM (Accepted Manuscript)

\section{PUBLISHER STATEMENT}

This is the peer reviewed version of the following article: HEANEY, L. ... et al, 2019. Evidence for alternative exhaled elimination profiles of disinfection by-products and potential markers of airway responses to swimming in a chlorinated pool environment. Indoor Air, 30 (2), pp.284-293, which has been published in final form at https://doi.org/10.1111/ina.12630. This article may be used for non-commercial purposes in accordance with Wiley Terms and Conditions for Use of Self-Archived Versions.

\section{LICENCE}

CC BY-NC-ND 4.0

\section{REPOSITORY RECORD}

Heaney, Liam, Shuo Kang, Matthew Turner, Martin Lindley, and Paul Thomas. 2019. "Evidence for Alternative Exhaled Elimination Profiles of Disinfection By-products and Potential Markers of Airway Responses to Swimming in a Chlorinated Pool Environment". Loughborough University. https://hdl.handle.net/2134/11322122.v1. 
Title: Evidence for alternative exhaled elimination profiles of disinfection by-products and potential markers of airway responses to swimming in a chlorinated pool environment

Running title: Metabolic responses to chlorine DBP exposure

Authors: Liam M Heaney ${ }^{1}$, Shuo Kang ${ }^{2}$, Matthew A Turner ${ }^{2}$, Martin R Lindley ${ }^{1,3 *}$, CL Paul Thomas $^{2 *}$

\section{Author affiliations:}

${ }^{1}$ School of Sport, Exercise and Health Sciences, Loughborough University, Loughborough, LE11 3TU, UK

2 Centre for Analytical Science, Department of Chemistry, Loughborough University, Loughborough, LE11 3TU, UK

3 Translational Chemical Biology Research Group, Loughborough University, Loughborough, LE11 3TU, UK

\section{Corresponding authors:}

* Dr Martin Lindley, School of Sport, Exercise and Health Sciences, Loughborough University, Loughborough, LE11 3TU, UK. Email: M.R.Lindley@Lboro.ac.uk

* Professor CL Paul Thomas, Centre for Analytical Science, Department of Chemistry, Loughborough University, Loughborough, LE11 3TU, UK. Email: C.L.P.Thomas@Lboro.ac.uk

\section{Competing Financial Interests:}

The authors declare they have no actual or potential competing financial interests. 


\title{
Acknowledgements
}

The authors thank gratefully the staff of Loughborough Sport's Swimming Pool (Loughborough University) and the volunteers who participated in this study. The authors also thank Loughborough University Graduate School for providing a $\mathrm{PhD}$ bursary and support for Liam M. Heaney.

\begin{abstract}
Chlorine-based disinfectants protect pool water from pathogen contamination but produce potentially harmful halogenated disinfection by-products (DBPs). This study characterized the bioaccumulation and elimination of exhaled DBPs post-swimming and investigated changes in exhaled breath profiles associated with chlorinated pool exposure. Nineteen participants provided alveolar-enriched breath samples prior to and 5, 90, 300, 510 and 600 min post-swimming. Known DBPs associated with chlorinated water were quantitated by thermal desorption-gas chromatography-mass spectrometry. Two distinct exhaled DBP elimination profiles were observed. Most participants (84\%) reported peak concentrations immediately post-swimming that reduced exponentially. A sub-group exhibited a previously unobserved and delayed washout profile with peak levels at 90 min post-exposure. Metabolomic investigations tentatively identified two candidate biomarkers associated with swimming pool exposure, demonstrating an upregulation in the hours after exposure. These data demonstrated a hitherto undescribed exhaled DBP elimination profile in a small number of participants which contrasts previous findings of uniform accumulation and exponential elimination. This sub-group which exhibited delayed peak-exhaled concentrations suggests the uptake, processing and immediate elimination of DBPs is not ubiquitous across individuals as previously understood. Additionally, nontargeted metabolomics highlighted extended build-up of compounds tentatively associated to swimming in a chlorinated pool environment that may indicate airway responses to DBP exposure.
\end{abstract}




\section{Practical Implications}

Swimming is an easily accessible and reduced impact exercise modality promoted for benefits to health, fitness and well-being. The use of disinfection agents to ensure water safety leads to the generation of hazardous chemicals that are potential carcinogens (e.g. chloroform). This research demonstrates for the first time that the rapid bioaccumulation and elimination of some of these compounds following exposure is not uniform across individuals as previously considered, and initial data suggest potential airway responses to chemical insult following swimming. This changes the landscape of what was previously understood and demonstrates the need to further understand the biological impact of these disinfection by-products.

\section{Key words}

Disinfection by-products; exposure; exhaled breath; metabolomics; breathomics; elimination 


\section{Introduction}

Swimming is the most popular recreational sporting activity in the United Kingdom. Survey data (2015/2016) report that approximately 2.5 million adults aged 16 years or over participate in at least one $30 \mathrm{~min}$ swimming session per week. ${ }^{1}$ Protection from crossinfection of swimming pool users is typically achieved with water treatment by sodium hypochlorite solution and/or chlorine. ${ }^{2}$ An average swimmer will contaminate swimming pool water with bodily secretions of urine (estimated at $50 \mathrm{~mL} / \mathrm{hr}$ ) and sweat (estimated at $100 \mathrm{~mL} / \mathrm{hr}){ }^{3}$ as well as externally applied lotions and cosmetics washed from the skin. ${ }^{4}$ These contaminants react with chlorine, and bromine, in the water to form volatile halogenated compounds termed disinfection by-products (DBPs). The most abundant DBPs are trihalomethanes, with chloroform reported at the highest concentrations, and haloacetic acids notably di- and trichloroacetic acid ${ }^{5,6}$ If inorganic bromine is present in the water, brominated by-products such as bromoform and bromodichloromethane will be formed. Additionally, haloamines are produced including trichloramine which is a volatile respiratory irritant with a smell redolent of the "chlorine-odor" of swimming pools.,

Due to the volatility of many DBPs, they are readily released from swimming pool water (which is commonly heated) into the surrounding environment in gaseous form, with elevated levels of water disturbance (i.e. splashing) leading to increased airborne concentrations. ${ }^{9}$ Consequently, swimmers and poolside attendants are exposed to the inhalation of DBPs which can then be passed into the circulatory system via alveolar gas exchange. ${ }^{10}$ Swimmers further encounter additional exposure routes including dermal absorption and ingestion. ${ }^{11,12}$ These exposures have led to the swimming pool chlorine paradox in which it is discussed that exercise through swimming has positive health benefits, while at the same time acting as a health risk factor because of exposure to disinfection agents and their by-products. ${ }^{13}$ The 
microbiological safety of swimming pool water is of first importance, with the unintended consequence of exposure to DBPs being a secondary, yet important issue. Such exposures are associated with adverse effects to eyes, skin, mucus membranes, respiratory health, as well as an elevated bladder cancer risk. ${ }^{6,14}$ Swimming pool attendance throughout childhood has further been associated with the development of asthma. ${ }^{15}$ Indeed, there is accumulating body of evidence associating exposure to swimming pool atmospheres with respiratory tract irritation, ${ }^{16-20}$ although some reports have failed to support these findings. ${ }^{21-23}$ A substantive review by Florentin et al. provides a valuable oversight of the many and varied factors associated with the health effects of exposure to swimming pools. ${ }^{24}$

Multiple studies have noted increased levels of DBPs measured in the breath and/or blood of swimmers and poolside attendees following exposure to the swimming pool environment. ${ }^{25}$ This has further led to an interest in the uptake and elimination of DBPs from biological systems. ${ }^{10,12,26-30}$ A particular focus has been placed on the measurement of exhaled levels as an indicator of the time taken to process and remove any initial DBP insult. ${ }^{25}$ An early investigation compared pre- and post-swimming levels of exhaled chloroform and mapped these against participant blood samples as well as environmental samples (pool water and environmental air). ${ }^{10}$ Chloroform was found to be present in all water $(19-94 \mu \mathrm{gLL})$ and air (49 - $280 \mathrm{ng} / \mathrm{L})$ samples. Although some breath samples demonstrated trace levels of chloroform pre-swimming (ca. $1 \mathrm{ng} / \mathrm{L}$ ), a rise in exhaled concentrations post-swimming was reported for all participants $(14-312 \mu \mathrm{g} / \mathrm{L})$, with a similar pattern recognized in matched blood samples. This was suggestive of accumulation during swimming followed by release, with the ability for DBP uptake into the blood from the alveoli. Whilst these data demonstrated accumulation, a later study sought to understand more clearly the process and rate in which accumulation occurred during swimming. ${ }^{28}$ Samples of $1 \mathrm{~L}$ (using a breath 
canister method) were collected from a single male and female participant at intervals during a $2 \mathrm{hr}$ training session. A well-defined build-up of trihalomethanes in the swimmers' breath was observed that indicated trans-dermal uptake was significant, estimated at ca. $80 \%$. More recently, a study measured levels of DBP in breath pre- and post-swimming with pre-exercise chloroform in exhaled breath rising from trace levels to $2.5-25 \mathrm{ng} / \mathrm{L}$ post-swimming. ${ }^{31}$

These studies have also sought to examine the elimination of DBPs following chlorine-pool exposure, albeit current data rely heavily on case studies or low participants numbers. Aggazzotti et al. followed a single participant for up to $10 \mathrm{hr}$ post-swimming and observed a first-order, one-compartment elimination of chloroform from exhaled breath. ${ }^{10}$ Low levels of chloroform were detectable at $10 \mathrm{hr}$, however, inconsistent measurements were collected over the four repeated sessions with little or no presence in breath from the 135 min postswimming collection point. This is potentially attributable to the inability for the low sample volume collected to reliably detect chloroform at trace concentrations. A more recent study characterized breath and urine concentrations of chloroform and bromodichloromethane following exposure to the swimming pool environment. ${ }^{27}$ The elimination profiles observed in 3 swimmers and 3 pool-workers had exponential washout characteristics, with breath concentrations returning to pre-exposure levels after $240 \mathrm{~min}$.

Nontargeted metabolomics (termed breathomics when related to exhaled air samples) allows an unbiased examination of small molecule metabolites with the intent to prospect for novel associations with a stimulus (i.e. exposure). These techniques have received growing interest in exercise-based research in recent years for both breath and blood applications. ${ }^{25,32}$ Further to targeted investigations of DBPs in exhaled breath, a single investigation has been performed by researchers on the metabolic signature changes following swimming exercise 
in a chlorinated pool environment. van Veldhoven et al. performed nontargeted analyses on blood collections and noted that 293 analytical features were associated with swimming exercise and/or DBP exposure, with a total of 13 metabolite identifications provided. ${ }^{29}$ Samples were solely collected at pre- and $2 \mathrm{hr}$ post-swimming and therefore extended information of changes in metabolic signature post-chlorine pool exposure could not be elucidated.

The current study sought to characterize more completely the elimination of DBPs from exhaled breath following exposure to a chlorinated swimming pool. This was performed through an extended washout study (600 min) using a sensitive collection and analysis technique. A larger group of swimmers than has previously been described for washout studies of this length was applied. Additionally, metabolomic methodologies were applied to breath samples (breathomics) to further understand if exercising in a chlorinated swimming pool causes extended (10 hr) changes in exhaled breath VOC profiles. 


\section{Methods}

\section{Ethical approval}

The study was approved in its entirety by the Loughborough University Ethical (Human Participants) Sub-Committee under the reference R13-P100 and conformed to the standards set out in the Declaration of Helsinki. All participants took part voluntarily and had the experiment explained to them verbally and in a participant information sheet written in plain English. All participants gave written and informed consent and were free to exclude themselves and their data from the experiment at any time without reason. After consent had been given, personal and private identifying information were separated from the experimental data which were assigned unique and anonymous identifier codes.

\section{Participant characteristics}

Nineteen healthy males were recruited to this study and none of the participants disclosed or showed signs of serious underlying medical conditions or impairing injuries. The cohort had the following characteristics (mean \pm SD): age $25 \pm 2$ yr; height $177 \pm 7 \mathrm{~cm}$; body mass 77.7 $\pm 11.2 \mathrm{~kg}$; body mass index (BMI) $24.8 \pm 3.0 \mathrm{~kg} . \mathrm{m}^{-2}$; estimated body surface area (BSA) 1.95 $\left.\pm 0.16 \mathrm{~m}^{2}\right) .{ }^{33}$ All participants fasted overnight (only water intake) and did not break their fast until after the post-swimming sample collection. No eating, drinking (except water) or tooth brushing was permitted in the preceding hour of subsequent sample collections, and caffeinated drinks were not permitted during the experimental time period. The participants completed a 30 min continuous swim at a challenging, yet maintainable, pace sustaining a target rating on Borg's scale of perceived exhaustion of 15 (classified as 'hard'). ${ }^{34}$ 
Participants were allowed to choose and alternate swimming stroke throughout the exercise session. The exercise started at the beginning of the first length $(25 \mathrm{~m})$ performed and ceased after the completion of the length being performed in which the 30 min time limit expired. All participants performed swimming exercise for 30 min covering $1.23 \pm 0.28 \mathrm{~km}$ under constant environmental conditions (pool area room temperature $24.5 \pm 0.7{ }^{\circ} \mathrm{C}$; relative humidity $57 \pm 8 \%$; and air pressure $757 \pm 7.8 \mathrm{mmHg}$ ). Participants were asked to briefly shower prior to and immediately following swimming. The use of cosmetic products (e.g. soap, shampoo etc.) was not permitted. All swimming sessions occurred in the morning at approximately 08:30 hrs.

\section{Sample acquisition}

Each participant provided six breath samples. A preliminary breath sample was taken ca. 5 min before the start of swimming and then at 5, 90, 300, 510 and 600 min after completion of the swim. Only single breath samples were collected and is therefore a limitation of the subsequent analyses. The pre-swimming and 5-min post-swimming samples were collected in a separated room located within the swimming pool complex and were collected prior to and after showering, respectively. All later samples (90- to 600-min post-swimming) were collected in a research laboratory located on the Loughborough University campus. Alveolarair enriched end-tidal breath samples ( $2 \mathrm{~L}$ ) were acquired using an adaptive breath sampling approach that has been described previously and modified with a portable purified air supply to the face mask (Figure 1). ${ }^{35}$ In brief, compressed ambient air was supplied by a marine diaphragm pump (HIBLOW linear air pump HP-200, Techno Takatsuki, Osaka, Japan) to a three-stage purification process, before being fed to supply the sampling mask. Air supply connections were push-fit silicon tubing and were regularly conditioned in a vacuum oven. 
Compressed air was dehumidified by passing it through a custom-made stainless-steel vessel containing a molecular sieve (Acros Organics, Fisher Scientific, Loughborough, UK). Then artefact VOCs were removed by passing the air through a bed of granular activated charcoal 4 to 8 mesh (Sigma-Aldrich, Gillingham, UK), housed in a stainless-steel vessel. The final stage was a respirable dust and particulate filter (See Figure 1). Environmental and purified air supply samples were also taken for each participant. Environmental air samples (2L) were collected using a sample pump (regulated at $0.5 \mathrm{~L} / \mathrm{min}$ for $4 \mathrm{~min}$; Escort ELF, MSA, UK) connected in reverse to the adsorbent sampling tubes. These environmental blanks were collected for ambient air at all sampling locations and at pool side (collected approximately 3 $\mathrm{m}$ from the pool edge) and analyzed using the same methods as exhaled samples. Purified air samples were collected by connecting the portable air purifying device onto the adsorbent sampling tube until a total of $2 \mathrm{~L}$ of purified air had been sampled (regulated at $0.5 \mathrm{~L} / \mathrm{min}$ for $4 \mathrm{~min}$ ) and were collected from the two breath sampling locations. Purified air samples were used as blank samples and interrogated for VOC contamination of the air supplied to the mask. The adsorbent sampling tubes were packed with a hydrophobic dual-bed absorbent mixture of Tenax TA and Carbograph 1TD (Markes International, Llantrisant, UK; part code C2-AXXX-5032). All adsorbent tubes were pre-conditioned using a commercial thermal desorption tube conditioner (TC-20, Markes International, Llantrisant, UK), followed by 'thermal polishing' with purified helium at $300{ }^{\circ} \mathrm{C}$ for $10 \mathrm{~min}$. Sample tubes were sealed and stored in an airtight storage box at $4{ }^{\circ} \mathrm{C}$ until analysis. 


\section{Experimental conditions}

The study was performed at the Loughborough Sport swimming pool located on Loughborough University campus. The swimming pool water is drawn from the local drinking water system and is disinfected using sodium hypochlorite $\left(\mathrm{NaClO}_{(\mathrm{aq})}\right)$ maintained at a recommended concentration of $1 \mathrm{mg} / \mathrm{L}$ with automatic electronic dosing pumps (TEKNA EVA TPG, Crius System, Pi, UK). NaClO has a permitted concentration range within the pool environment of between $0.5-5 \mathrm{mg} / \mathrm{L}$ and is deemed as non-hazardous. Ultraviolet light disinfection is also used. Due to the basic nature of $\mathrm{NaClO}$, a solution of hydrochloric acid $(\mathrm{HCl})$ is introduced into the swimming pool water. The $\mathrm{HCl}$ was supplied as concentrate (32\% to $38 \%$ aqueous solution) and was diluted before being mixed into the pool water. The permitted concentration range for $\mathrm{HCl}$ in the pool water is $7.2-7.6 \mathrm{mg} / \mathrm{L}$, with a recommended value of $7.4 \mathrm{mg} / \mathrm{L}$. The pool contains approximately $2,500 \mathrm{~m}^{3}$ of water and, with the pumps running at full capacity, has a turnover time of approximately $5.5 \mathrm{hr}$. The pool water is maintained at a temperature of $27.8 \pm 0.1^{\circ} \mathrm{C}$.

\section{Sample Analysis}

Before analysis, adsorbent tubes were allowed to equilibrate to room temperature and then spiked with $0.1 \mu \mathrm{l}$ of toluene-D8 in methanol $(200 \mu \mathrm{g} / \mathrm{mL})$ by fitting the tube to an injector supplied with purified nitrogen at a flow of $100 \mathrm{~mL} / \mathrm{min}$. The adsorbent sample tube was connected to the injector for $60 \mathrm{~s}$ to ensure complete transfer of the internal standard. All samples were analyzed by thermal desorption-gas chromatography-ion trap mass spectrometry (TD-GC-MS), see Table S1 and the previous publication by Turner et al. ${ }^{36}$ Splitless thermal desorption (Unity TD Unit Markes Int, Llantrisant, UK) at $300{ }^{\circ} \mathrm{C}$ for $5 \mathrm{~min}$ 
with a helium desorption flow of $45 \mathrm{~mL} / \mathrm{min}$ to a general purpose hydrophobic cold trap held at $-10{ }^{\circ} \mathrm{C}$ was used to recover and preconcentrate sampled VOCs. Splitless injection to the GC was achieved with ballistic heating of the cold trap to $300{ }^{\circ} \mathrm{C}$ for 5 min with helium carrier gas $(2 \mathrm{~mL} / \mathrm{min})$ via a deactivated silica capillary $(0.25 \mathrm{~mm}$ id, $1 \mathrm{~m} \mathrm{long})$ transfer line maintained at $180{ }^{\circ} \mathrm{C}$. Mass spectral acquisition was performed using electron impact ionization over a scan range of $\mathrm{m} / \mathrm{z} 40-450$ for a total run time of $60 \mathrm{~min}$. Figure 2 is an example breath chromatogram showing extracted ion chromatograms for DBPs of interest (chloroform, bromodichloromethane and dibromochloromethane). Samples were analyzed sequentially as a batch for each participant in order to avoid lengthy storage times following collection. All samples within each participant batch were randomized to minimize intrabatch bias. Intra- and inter-batch deviations were minimized through the adjustment of data outputs to the doped toluene-D8 standard. Daily quality control checks were performed on the TD-GC-MS instrument through the injection of a multi-component in-house check mixture containing a range of $n$-alkanes, chloroalkanes and alcohols. ${ }^{37}$ No samples were analyzed until these performance checks were satisfactorily achieved.

\section{Data Analysis}

Targeted DBP analytes were identified using Varian MS Workstation (v. 6.9.2, Varian Inc. now Agilent Technologies, Palo Alto, CA, USA) by confirmation of mass spectra and retention time compared against a multi-component mixture analytical standard $(100 \mu \mathrm{g} / \mathrm{mL}$ in methanol, KDWR VOC Mix B, product code: 506583: Sigma-Aldrich, Gillingham, UK). The multi-component mixture was diluted in methanol and loaded onto adsorbent tubes by fitting to an injector supplied with purified nitrogen at a flow of $100 \mathrm{~mL} / \mathrm{min}$ as described for the loading of the toulene-D8 internal standard. The standards were diluted directly in solvent 
prior to loading and therefore recoveries were not tested. Calibration analyses were performed over 10 points between 0.02 and $40 \mathrm{ng} / \mathrm{L}$ and were linear in profile $\left(\mathrm{r}^{2} \geq 0.998\right)$. Quantitative values for DBP concentration were generated using calibration data obtained via analyses of the standard. All reported exhaled DBPs of interest were detectable at the lowest performed calibration point which was deemed as suitable for the present investigation and therefore values for the lower limits of detection and quantitation were not determined; these were $0.02 \mathrm{ng} / \mathrm{L} \quad$ (chloroform) and $0.04 \mathrm{ng} / \mathrm{L}$ (bromodichloromethane and dibromochloromethane).

For metabolomic investigation, data were exported from the Varian operating system and peak deconvolution performed by AnalyzerPro (SpectralWorks, Runcorn, UK). Each VOC identified from deconvoluted data was assigned a unique identifier and peak integration parameters were optimized for each candidate compound enabling peak integration data to be exported to an exhaled VOC breath matrix.

Targeted statistical analyses were performed using IBM SPSS Statistics (v 22.0, IBM Corp., Endicott, NY, USA) to assess changes in post-exercise concentrations of DBPs in exhaled breath. Wilcoxon signed rank tests were performed to compare DBP concentrations in breath samples over the 600 min study to pre-exercise values. Bonferroni correction was used to account for multiple comparisons, and therefore all $p$ values refer to the Bonferroni adjusted value. A $p$ value of $<0.05$ was deemed as statistically significant.

Multivariate metabolomic profiling was performed using SIMCA-P+ software ( $\mathrm{v} 14$, Umetrics, Umeå, Sweden). Variables (exhaled VOC levels) were unit variance (UV) scaled before orthogonal partial least squares-discriminant analysis (OPLS-DA) was applied to 
identify VOCs that enabled pre-defined classes of data to be separated. The contribution of each VOC to the separation of the different classes was evaluated with a model contribution plot, known as an S-plot, to identify the VOCs that had the greatest sensitivity and selectivity in discriminating between data classes (Figure S1). These were the compounds present at the extremes of the S-plot, which were then extracted from the data matrix for further investigation. ${ }^{38}$ 


\section{Results}

\section{DBP elimination}

Two different patterns of exhaled DBP elimination profile were observed for chloroform and dibromochloromethane, with bromodichloromethane showing similar elimination behavior across the cohort (Figure 3). For chloroform and dibromochloromethane, most participants (n = 16) exhibited an exhaled DBP elimination profile consistent with those described previously, with exhaled breath concentrations reducing exponentially from a maximum observed in the immediacy after swimming; see Table 1 and Figure 4. Environmental (pool and sampling room air) and purified air DBP concentrations are further included in Table 1. Interestingly, a sub-group of participants exhibited a previously unobserved and delayed washout profile with peak levels being observed at or maintained until the 90 min sampling point (Figure 3). For the participants exhibiting a common washout profile, median exhaled concentrations of chloroform increased 121-fold and remained above pre-swimming levels until at least 300 min post-swimming $(p \leq 0.04)$. Levels of exhaled chloroform returned to pre-swimming levels by $510 \mathrm{~min}$ post-swimming $(p=0.08)$. Similarly, median exhaled concentrations of bromodichloromethane increased 4.4-fold post-swimming and remained above pre-swim levels until at least $90 \mathrm{~min}$ post-exercise $(p \leq 0.02)$. Elevated levels of dibromochloromethane were observed only in samples collected at 5 min post-swimming (median 1.8-fold increase; $p=0.02$ ). Due to the unexplained differences in the washout profiles, only the majority group $(n=16)$ were taken forward for metabolomic investigation. 


\section{Metabolic profiling}

Six hundred and three unique VOC peaks were isolated from the breath samples, with 73 of these VOCs present in more than $20 \%$ of the breath samples and less than $20 \%$ of the environment samples. OPLS-DA indicated the presence of discriminating compounds preand 600 min post-swimming and a panel of four candidate discriminating VOCs which showed upregulation were identified from the S-plot, see Figure S1. The four upregulated responses were investigated as potential metabolite signatures of DBP exposure. Two of these were identified as siloxanes that are commonly associated with GC column bleed artefacts generated from exhaled breath samples and were therefore removed from further consideration. The remaining two upregulated compounds were tentatively identified as benzofuran-2-carboxaldehyde and (5E)-6,10-dimethylundec-5,9-dien-2-one also known as geranylacetone (Table 2). In this instance, the focus of the experiment was to assess the potential production of compounds associated with exercise in a chlorinated environment and therefore downregulated compounds were not investigated further.

The ion abundances for these two compounds were scaled for each participant to the maximum observed intensity across the $600 \mathrm{~min}$ study. The ion scores were combined into a Euclidean distance for each sampling time point and the upregulation of the combined ions' score was statistically significant at the time points of $510 \mathrm{~min}$ and $600 \mathrm{~min}(p \leq 0.032)$. Figure 5 shows the trends in these data. 


\section{Discussion}

The present investigation supports previous data to demonstrate the expected post-swimming rise and exponential elimination of halogenated DBPs in the exhaled breath of participants following swimming exercise in a chlorinated pool environment. For the case of chloroform, as the most abundant DBP, levels did not return to pre-swimming levels until after the $8.5 \mathrm{hr}$ sampling point. Interestingly, it has further demonstrated a minority sub-group which exhibited a delay in peak levels of two exhaled DBPs. These data suggest that the uptake, processing and immediate elimination of DBPs is not ubiquitous across individuals and may have only been possible to detect following the application of a more sensitive collection and analysis technique to previous investigations (i.e. increased volume of collection and reduced environmental contamination). In addition, non-targeted breathomic workflows highlighted a metabolic signature that relates to the extended build-up of compounds that are tentatively associated to swimming exercise within a chlorinated environment.

This study has expanded the number of participants recruited into an extended washout study. Considerable inter-subject variability of DBP levels was observed and this factor was further complicated by hitherto undescribed delayed elimination profiles that cannot be accounted for by washout from exposure exclusively through respiratory and dermal routes. Three participants $(16 \%)$ exhibited markedly different elimination profiles with a delayed washout of chloroform and dibromochloromethane. For chloroform, two of these participants had maximum exhaled concentrations at the 90 min post-swimming sampling point, and one participant showing elevated levels at the $5 \mathrm{~min}$ and $90 \mathrm{~min}$ post-swimming. The 5-point sampling design was created to monitor an exponential washout centered on a sampling time of $300 \mathrm{~min}$. The sampling times at $5 \mathrm{~min}$ and 90 min lacked the time discrimination required to better define the exposure and elimination behaviors associated with this sub-group. Whilst 
theoretically the delayed presence in breath could be associated with ingestion and subsequent processing of DBPs, the total contribution of this route is known to be minimal for trihalomethanes and therefore unlikely to have produced this phenomenon. ${ }^{39}$ Future assessments of DBP exposures can exclude this potential exposure by specifying exercise protocols in the pool that prevent pool water ingestion (i.e. performed at poolside or without submerging the head), however it is considered that the exposure would be unlikely to have such profound impact on the washout profile. ${ }^{39,40}$ One potential confounder may be the compartmentalization of DBPs into body fat, ${ }^{41-44}$ however, it is not possible to attribute this biological mechanism with the current data and therefore further study is required. Individuals who exhibited delayed washout characteristics were, on average, lighter (expected vs delayed washout profile; mean values; 79.0 vs $70.7 \mathrm{~kg})$, shorter (178 vs $172 \mathrm{~cm})$ and therefore had reduced BSA (1.97 vs $1.84 \mathrm{~m}^{2}$ ). In addition, these participants also, on average, swam further (1153 vs $1417 \mathrm{~m}$ ), see Table S2. However, current data should be considered with caution and a further study with increased participant number and increased sampling frequency is suggested.

In order to better capture inter-subject variability in the washout of DBP, future studies would be improved by applying collections at sample times of 5, 15, 40, 90 and 510 min postswimming. This would fit a central composite design to the washout dynamic observed for the majority of the participants while allowing for any delayed washout phenomena to be better captured. The application of on-line breath-by-breath analysis with compact mass spectrometric techniques may also be usefully considered. ${ }^{45}$

For the nontargeted breathomic analyses, two compounds were identified as increasing in exhaled concentration during the washout period of DBPs. These were tentatively identified 
(geranylacetone). Benzofuran-2-carboxaldehyde is described in the Human Metabolome Database as a nutrient and food flavoring expected to be found at unquantified concentrations in cytoplasm and extracellular material. ${ }^{46}$ Aldehyde compounds in breath have been associated with inflammation/oxidative stress responses. ${ }^{47-50}$ Elevated levels of this compound were observed in approximately one quarter of the participants, and it would be premature to attribute this to a post-swimming inflammatory response. Nevertheless, a further study with targeted analysis is warranted. Geranylacetone is a monoterpene that contains a chain of two isoprene units and is associated with the mevalonate pathway and characterized as an endogenous metabolite associated with: cell signaling, energy storage and membrane integrity. The metabolomic ontology of geranylacetone indicates that it is located within membranes and extracellular fluids ${ }^{51}$ Geranylacetone has also been identified as a product of ozonolysis of skin lipids and may be produced from sesquiterpenes through the oxidative cleavage at an alkene site leaving the ketone. ${ }^{52}$ Geranylacetone has also been cited as a secondary metabolite as a diagnostic for invasive aspergillosis where it was proposed to be produced as a secondary metabolite from sesquiterpenes associated with the Aspergillus infiltrate, ${ }^{53}$ however the proposition that the geranylacetone was derived from inflammation or tissue damage was not discussed. The raised levels of these compounds may be associated with exercise and metabolism, environmental/dietary factors, random correlation, their release through tissue injury, or by their production through reactive oxidative stress resulting from chlorine exposure; therefore, further investigations are required to elucidate the biological pathways involved.

In conclusion, this study demonstrated two distinct washout profiles associated with exposure to known halogenated DBPs following a 30 min swimming intervention in a chlorinated pool 
environment. The majority of participants showed washout profiles that mirrored previous findings, with a small sub-set exhibiting a delay in peak exhaled concentration. Furthermore, detectable changes in the endogenous exhaled breath VOC profile were observed during the extended washout period. Scaled exhaled concentrations of two endogenous compounds (benzofuran-2-carboxaldehyde and geranylacetone) were observed to increase, reaching significantly elevated levels at 510 and 600 min post-swimming. Geranylacetone was the most significant contributor, however the high inter-subject variability, see Figure 5, was a confounding factor and, therefore, a study with increased statistical power to allow adjustment for confounding variables (e.g. body mass, distance swam etc.) is required to verify this observation. Targeted prospective studies involving increased participant numbers with stratified respiratory rates and exposures, alongside comparisons made to natural or nonchlorinated disinfection methods, would enable these putative markers of inhalation injury to be followed up and verified. 


\section{References}

1. Sport England. Active People Survey 10 October 2015 - September 2016. Once a Week Participation in Funded Sports amongst People Aged 16 Years and Over. Vol 10.; 2016. 2016. https://www.sportengland.org/media/11746/1x30_sport_16plusfactsheet_aps10.pdf.

2. Chowdhury S, Alhooshani K, Karanfil T. Disinfection byproducts in swimming pool: Occurrences, implications and future needs. Water Res. 2014;53:68-109.

3. Judd S., Bullock G. The fate of chlorine and organic materials in swimming pools. Chemosphere. 2003;51:869-879.

4. World Health Organization. Volume 2: Swimming Pools and Similar Environments. 2006. https://www.who.int/water_sanitation_health/bathing/srwe2full.pdf.

5. Kim H, Shim J, Lee S. Formation of disinfection by-products in chlorinated swimming pool water. Chemosphere. 2002;46:123-130.

6. Richardson SD, DeMarini DM, Kogevinas M, et al. What's in the Pool? A Comprehensive Identification of Disinfection By-products and Assessment of Mutagenicity of Chlorinated and Brominated Swimming Pool Water. Environ Health Perspect. 2010;118:1523-1530.

7. Schmalz C, Wunderlich HG, Heinze R, Frimmel FH, Zwiener C, Grummt T. Application of an optimized system for the well-defined exposure of human lung cells to trichloramine and indoor pool air. J Water Health. 2011;9:586-596.

8. Weng S, Blatchley ER. Disinfection by-product dynamics in a chlorinated, indoor swimming pool under conditions of heavy use: National swimming competition. Water Res. 2011;45:5241-5248.

9. Chu H, Nieuwenhuijsen MJ. Distribution and determinants of trihalomethane concentrations in indoor swimming pools. Occup Environ Med. 2002;59:243-247. 
10. Aggazzotti G, Fantuzzi G, Righi E, Predieri G. Environmental and biological monitoring of chloroform in indoor swimming pools. J Chromatogr A. 1995;710:181190.

11. Xiao F, Zhang X, Zhai H, et al. New Halogenated Disinfection Byproducts in Swimming Pool Water and Their Permeability across Skin. Environ Sci Technol. 2012;46:7112-7119.

12. Caro J, Gallego M. Assessment of Exposure of Workers and Swimmers to Trihalomethanes in an Indoor Swimming Pool. Environ Sci Technol. 2007;41:47934798.

13. Bougault V, Turmel J, Levesque B, Boulet L-P. The Respiratory Health of Swimmers. Sport Med. 2009;39:295-312.

14. Zwiener C, Richardson SD, De Marini DM, Grummt T, Glauner T, Frimmel FH. Drowning in Disinfection Byproducts? Assessing Swimming Pool Water. Environ Sci Technol. 2007;41:363-372.

15. Andersson M, Hedman L, Nordberg G, Forsberg B, Eriksson K, Rönmark E. Swimming pool attendance is related to asthma among atopic school children: a population-based study. Environ Heal. 2015;14:37.

16. Bohadana AB, Massin N, Toamain JP, Wild P, Hery M, Hubert G. Respiratory symptoms and bronchial responsiveness in lifeguards exposed to nitrogen trichloride in indoor swimming pools. Occup Environ Med. 2009;55:258-263.

17. Bougault V, Boulet L-P. Airway dysfunction in swimmers. Br J Sports Med. 2012;46:402-406.

18. Weisel CP, Richardson SD, Nemery B, et al. Childhood Asthma and Environmental Exposures at Swimming Pools: State of the Science and Research Recommendations. Environ Health Perspect. 2009;117:500-507. 
19. Bougault V, Boulet L-P. Airways Disorders and the Swimming Pool. Immunol Allergy Clin North Am. 2013;33:395-408.

20. Bernard A, Nickmilder M, Dumont X. Chlorinated pool attendance, airway epithelium defects and the risks of allergic diseases in adolescents: Interrelationships revealed by circulating biomarkers. Environ Res. 2015;140:119-126.

21. Valeriani F, Protano C, Vitali M, Romano Spica V. Swimming attendance during childhood and development of asthma: Meta-analysis. Pediatr Int. 2017;59:614-621.

22. Font-Ribera L, Villanueva CM, Gràcia-Lavedan E, Borràs-Santos A, Kogevinas M, Zock J-P. Indoor swimming pool attendance and respiratory and dermal health in schoolchildren - HITEA Catalonia. Respir Med. 2014;108:1056-1059.

23. Font-Ribera L, Villanueva CM, Ballester F, et al. Swimming pool attendance, respiratory symptoms and infections in the first year of life. Eur J Pediatr. 2013;172:977-985.

24. Florentin A, Hautemanière A, Hartemann P. Health effects of disinfection by-products in chlorinated swimming pools. Int J Hyg Environ Health. 2011;214:461-469.

25. Heaney LM, Lindley MR. Translation of exhaled breath volatile analyses to sport and exercise applications. Metabolomics. 2017;13:139.

26. Aggazzotti G, Fantuzzi G, Righi E, Predieri G. Blood and breath analyses as biological indicators of exposure to trihalomethanes in indoor swimming pools. Sci Total Environ. 1998;217:155-163.

27. Caro J, Gallego M. Alveolar Air and Urine Analyses As Biomarkers of Exposure to Trihalomethanes in an Indoor Swimming Pool. Environ Sci Technol. 2008;42:50025007. 
28. Lindstrom AB, Pleil JD, Berkoff DC. Alveolar breath sampling and analysis to assess trihalomethane exposures during competitive swimming training. Environ Health Perspect. 1997; 105:636-642.

29. van Veldhoven K, Keski-Rahkonen P, Barupal DK, et al. Effects of exposure to water disinfection by-products in a swimming pool: A metabolome-wide association study. Environ Int. 2018;111:60-70.

30. Aggazzotti G, Fantuzzi G, Tartoni PL, Predieri G. Plasma Chloroform Concentrations in Swimmers Using Indoor Swimming Pools. Arch Environ Health. 1990;45:175-179.

31. Font-Ribera L, Kogevinas M, Schmalz C, et al. Environmental and personal determinants of the uptake of disinfection by-products during swimming. Environ Res. 2016;149:206-215.

32. Heaney LM, Deighton K, Suzuki T. Non-targeted metabolomics in sport and exercise science. J Sports Sci. 2019;37:959-967.

33. Mosteller RD. Simplified Calculation of Body-Surface Area. N Engl J Med. $1987 ; 317: 1098$

34. Borg G. Psychophysical scaling with applications in physical work and the perception of exertion. Scand J Work Environ Health. 1990;16:55-58.

35. Basanta M, Koimtzis T, Singh D, Wilson I, Thomas CLP. An adaptive breath sampler for use with human subjects with an impaired respiratory function. Analyst. 2007;132:153-163.

36. Turner M, Guallar-Hoyas C, Kent A, Wilson I, Thomas C. Comparison of metabolomic profiles obtained using chemical ionization and electron ionization MS in exhaled breath. Bioanalysis. 2011;3:2731-2738. 
37. Guallar-Hoyas C, Turner M a, Blackburn GJ, Wilson ID, Thomas CP. A workflow for the metabolomic/metabonomic investigation of exhaled breath using thermal desorption GC-MS. Bioanalysis. 2012;4:2227-2237.

38. Wiklund S, Johansson E, Sjöström L, et al. Visualization of GC/TOF-MS-Based Metabolomics Data for Identification of Biochemically Interesting Compounds Using OPLS Class Models. Anal Chem. 2008;80:115-122.

39. Yang L, Chen X, She Q, et al. Regulation, formation, exposure, and treatment of disinfection by-products (DBPs) in swimming pool waters: A critical review. Environ Int. 2018;121:1039-1057.

40. Chowdhury S. Predicting human exposure and risk from chlorinated indoor swimming pool: a case study. Environ Monit Assess. 2015;187:502.

41. Riederer AM, Dhingra R, Blount BC, Steenland K. Predictors of Blood Trihalomethane Concentrations in NHANES 1999-2006. Environ Health Perspect. 2014;122:695-702.

42. Smith RB, Edwards SC, Best N, Wright J, Nieuwenhuijsen MJ, Toledano MB. Birth Weight, Ethnicity, and Exposure to Trihalomethanes and Haloacetic Acids in Drinking Water during Pregnancy in the Born in Bradford Cohort. Environ Health Perspect. 2016;124:681-689.

43. World Health Organization. Environmental Health Criteria for Disinfectants and Disinfectant By-Products; 2016. https://www.who.int/ipcs/publications/ehc/216_disinfectants_part_1.pdf

44. World Health Organization. Trihalomethanes in Drinking-Water; 2005. https://www.who.int/water_sanitation_health/dwq/chemicals/THM200605.pdf 
45. Heaney LM, Ruszkiewicz DM, Arthur KL, et al. Real-time monitoring of exhaled volatiles using atmospheric pressure chemical ionization on a compact mass spectrometer. Bioanalysis. 2016;8:1325-1336.

46. HMDB. Human metabolome database Metabocard for 2-benzofurancarboxaldehyde (HMDB33183). http://www.hmdb.ca/metabolites/HMDB33183. Accessed May 16, 2019.

47. Krilaviciute A, Heiss JA, Leja M, Kupcinskas J, Haick H, Brenner H. Detection of cancer through exhaled breath: a systematic review. Oncotarget. 2015;6:38643-38657.

48. Pereira J, Porto-Figueira P, Cavaco C, et al. Breath Analysis as a Potential and NonInvasive Frontier in Disease Diagnosis: An Overview. Metabolites. 2015;5:3-55.

49. Arasaradnam RP, Covington JA, Harmston C, Nwokolo CU. Review article: next generation diagnostic modalities in gastroenterology - gas phase volatile compound biomarker detection. Aliment Pharmacol Ther. 2014;39:780-789.

50. Berdyshev E V. Mass spectrometry of fatty aldehydes. Biochim Biophys Acta - Mol Cell Biol Lipids. 2011;1811:680-693.

51. HMDB. Human metabolome database Metabocard for geranlyacetone (HMDB31846). http://www.hmdb.ca/metabolites/HMDB31846. Accessed May 16, 2019.

52. Wisthaler A, Weschler CJ. Reactions of ozone with human skin lipids: Sources of carbonyls, dicarbonyls, and hydroxycarbonyls in indoor air. Proc Natl Acad Sci. 2010;107:6568-6575.

53. Koo S, Thomas HR, Daniels SD, et al. A Breath Fungal Secondary Metabolite Signature to Diagnose Invasive Aspergillosis. Clin Infect Dis. 2014;59:1733-1740. 
Table 1. Summary of elimination behaviors observed for three disinfection by-products (DBP) in 16 participants following 30 min exercise intervention in a chlorinated swimming pool.

\begin{tabular}{|c|c|c|c|c|}
\hline Compound & Sample ID & $\begin{array}{l}\text { Median exhaled DBP } \\
\text { conc. (ng/L) }\end{array}$ & $\begin{array}{l}\text { Median fold change } \\
\text { from pre-swimming }\end{array}$ & $p$-Value \\
\hline \multirow{8}{*}{ chloroform } & Pool air & $72.12(36.68$ to 223.15$)$ & & \multirow{5}{*}{$\begin{array}{l}<0.0005 \\
0.01\end{array}$} \\
\hline & Purified air & $0.30 \quad(0.17$ to 1.41$)$ & & \\
\hline & Pre-swim & $0.14 \quad(0.00$ to 0.71$)$ & & \\
\hline & +5 & 16.25 (2.88 to 26.01$)$ & 121.0 & \\
\hline & +90 & $2.83 \quad(1.14$ to 4.98$)$ & 21.1 & \\
\hline & +300 & 0.69 (0.09 to 1.68$)$ & 5.1 & 0.04 \\
\hline & +510 & $0.48 \quad(0.08$ to 0.81$)$ & 3.6 & 0.08 \\
\hline & +600 & $0.36 \quad(0.07$ to 0.78$)$ & & NS \\
\hline \multirow{10}{*}{ bromodichloromethane } & Pool air & $12.49(2.69$ to 23.51$)$ & & \\
\hline & Purified air & 0.36 (0.00 to 0.50$)$ & & \\
\hline & Pre-swim & 0.85 (0.00 to 1.36$)$ & & \\
\hline & +5 & $3.74(1.50$ to 11.37$)$ & 4.4 & 0.002 \\
\hline & +90 & $1.28(0.94$ to 1.84$)$ & 1.5 & 0.02 \\
\hline & +300 & $0.91 \quad(0.64$ to 1.20$)$ & 1.1 & NS \\
\hline & +510 & $0.87(0.64$ to 1.50$)$ & 1.0 & NS \\
\hline & +600 & $0.80 \quad(0.00$ to 1.98$)$ & 0.9 & NS \\
\hline & Pool air & $1.60(0.20$ to 3.51$)$ & & \\
\hline & Purified air & $0.14(0.00$ to 0.34$)$ & & \\
\hline \multirow{6}{*}{ dibromochloromethane } & Pre-swim & $0.29(0.00$ to 0.55$)$ & & \\
\hline & +5 & $0.51(0.30$ to 0.71$)$ & 1.8 & 0.002 \\
\hline & +90 & $0.34(0.29$ to 0.38$)$ & 1.2 & NS \\
\hline & +300 & $0.29(0.00$ to 0.32$)$ & 1.0 & NS \\
\hline & +510 & $0.29(0.00$ to 0.33$)$ & 1.0 & NS \\
\hline & +600 & $0.28(0.00$ to 0.37$)$ & 1.0 & NS \\
\hline
\end{tabular}

Note: All $p$-values refer to comparisons with pre-swimming samples. Exhaled DBP concentrations are reported as median (minimum to maximum) levels. NS $=p>0.05$. 
Table 2. Markers of swimming in a chlorinated pool environment identified from multivariate analysis of isolated exhaled volatile organic compounds.

Tentative assignment

(5E)-6,10-dimethylundec-5,9- dien-2-one

Benzofuran-2-carboxaldehyde
FM RM

$679 \quad 735$

$555 \quad 797$

Note: FM: forward match; RM: reverse match; $\boldsymbol{R I}_{\boldsymbol{o}}$ : observed retention index; $\boldsymbol{R} \boldsymbol{I}_{\boldsymbol{p}}:$ predicted retention index.

Search data refer to values obtained against the National Institute for Science and Technology (NIST) Mass Spectral Library. The forward match search assesses the comparison of the unknown mass spectrum against known spectrum profiles present within the database library. Reverse match searching ignores the spectral peaks present in the unknown spectrum that do not appear in the library spectrum and is therefore able to improve peak identification in samples with coeluting molecules or high background noise. A higher score (out of 999) indicates a good match between the spectra. 


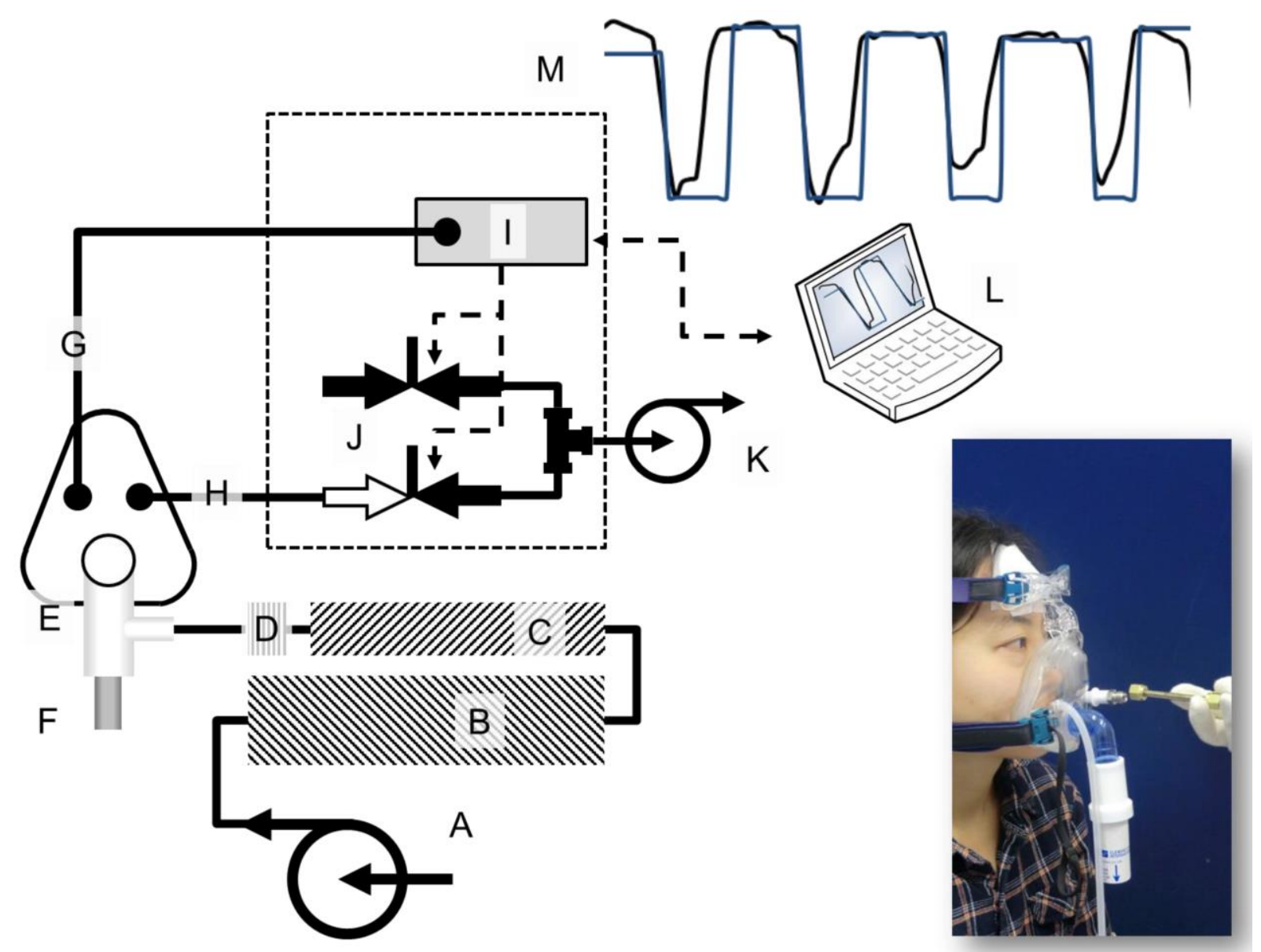

Figure 1. Schematic diagram of the adaptive breath sampler used to collect alveolar enriched breath samples. Inset image showing the breath mask fitted to a participant with (from left to right) a silicone tube connector to the pressure sensor, the air supply inlet with non-return valve on the exhaust, and the adsorbent trap being fitted to the mask prior to sampling.

Key: A: Pump; B: canister of molecular sieve; C: canister of activated charcoal; D: filter for respirable particulates; E: respiratory mask connected to air supply with a one-way nonrebreathing valve fitted to the exhaust; G: silicone tube connected to a pressure sensor in the sample control module; $\mathrm{H}$ : adsorbent trap connected by a silco steel capillary to the respiratory zone and connected by a silicone tubing to the control valve; I: sample control module; J: breath profile sample selection valve; K: sampling pump; L: laptop computer running virtual instrument; and, M: example breath pressure profile (black) overlaid with sample selection periods. 


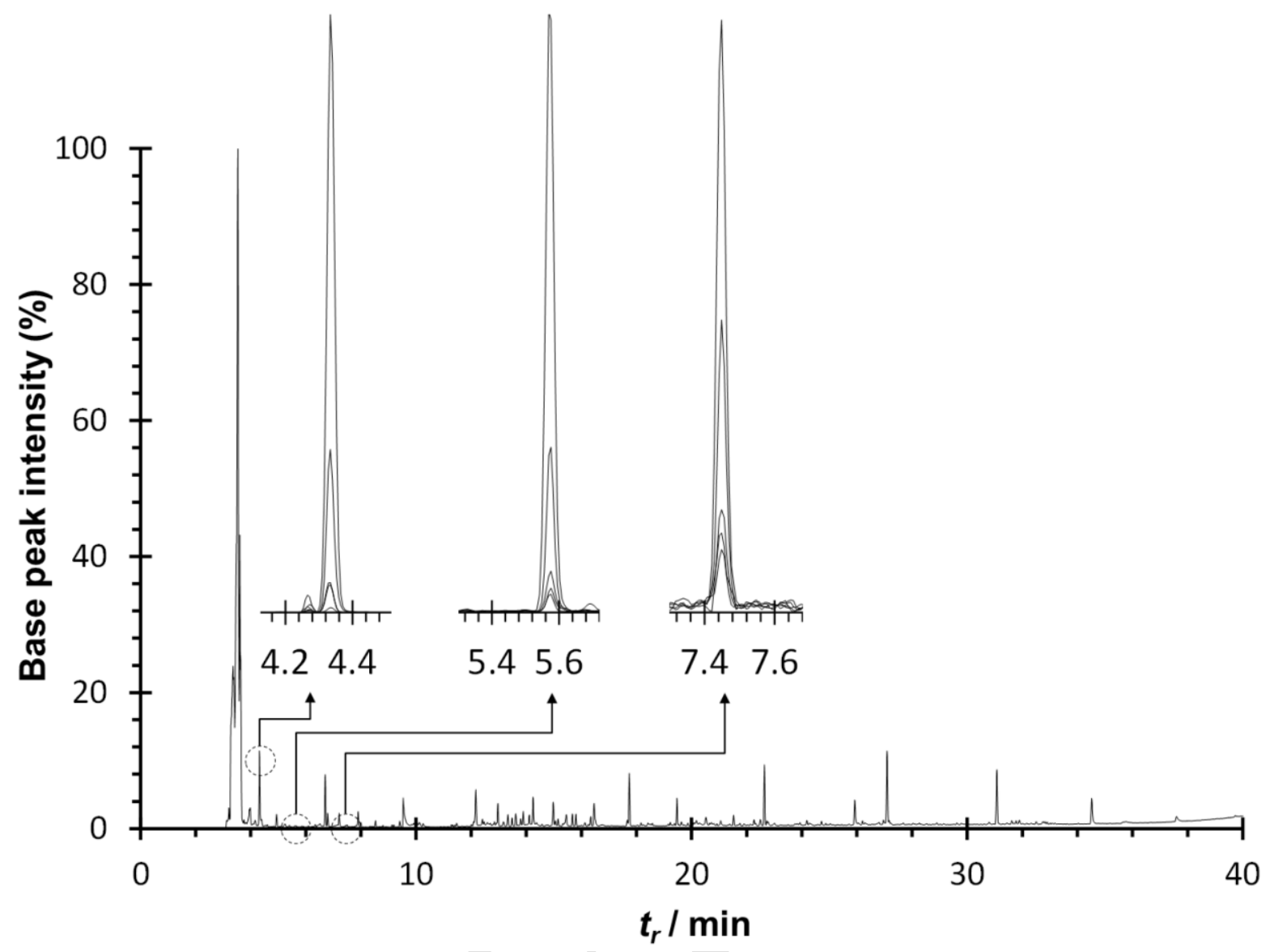

Figure 2. An example normalized pre-swim total-ion chromatogram from a single participant (main body) with normalized overlaid and aligned extracted ion chromatograms obtained at the five sampling times for chloroform $(\mathrm{m} / \mathrm{z}, 83$, left), bromodichloromethane ( $\mathrm{m} / \mathrm{z}, 83$, middle) and dibromochloromethane $(\mathrm{m} / \mathrm{z}, 129$, right).

Note: $t_{\mathrm{r}}=$ retention time. 


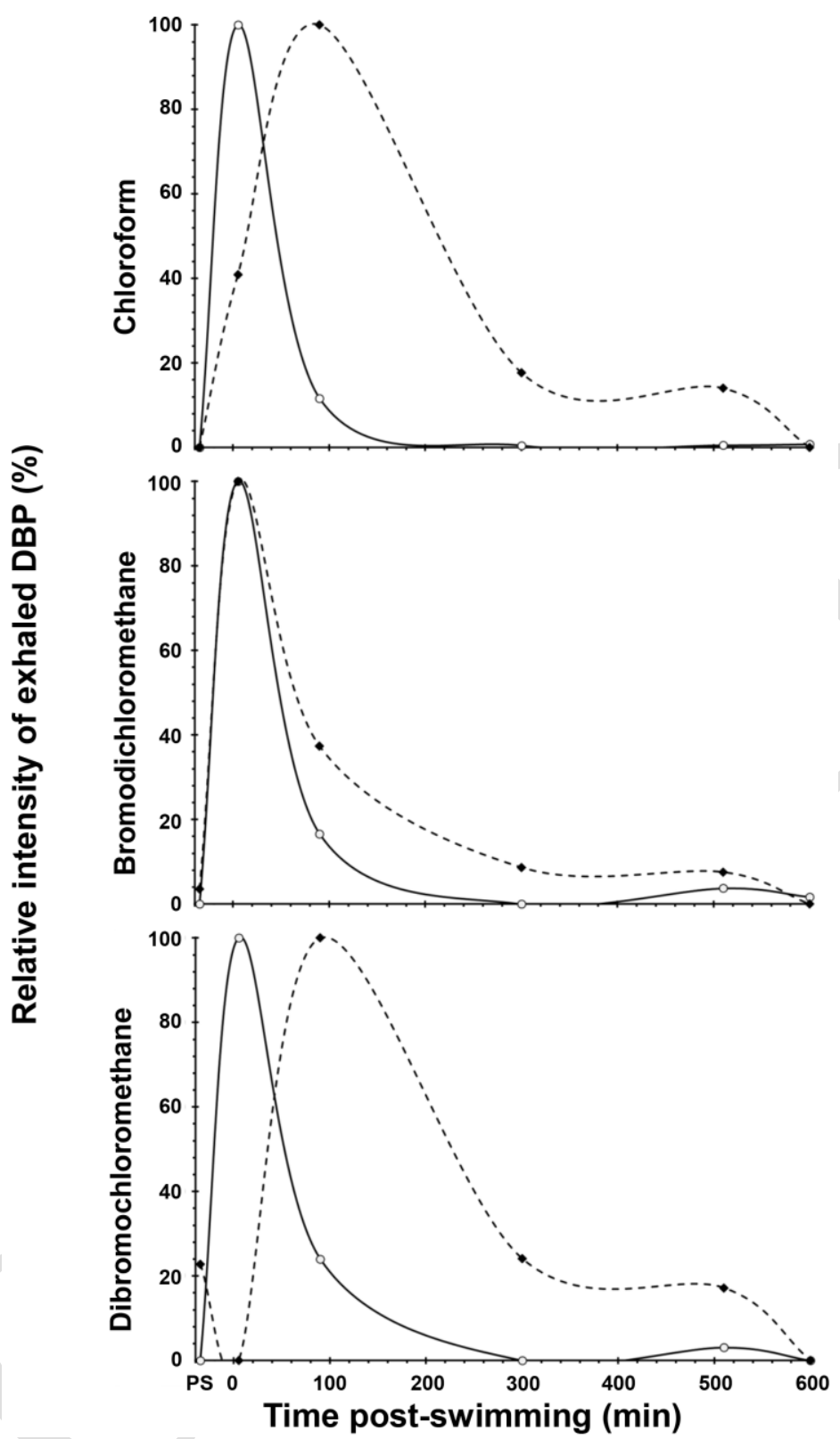

Figure 3. Example exhaled disinfection by-product washout profiles to show the comparison of inconsistent elimination behaviors observed within the cohort including an expected (Participant 08) and delayed (Participant 02) profile. These two participants had similar anthropometric and swimming performance characteristics (see Table S2). Interestingly, the delayed elimination profiles were noted in three individuals for chloroform and dibromochloromethane, but not for bromodichloromethane. Exhaled intensities are normalized to the highest concentration within each participant to visualize the differences in profile.

Note: PS indicates the relative exhaled concentrations of chloroform present in the preswimming sample. 

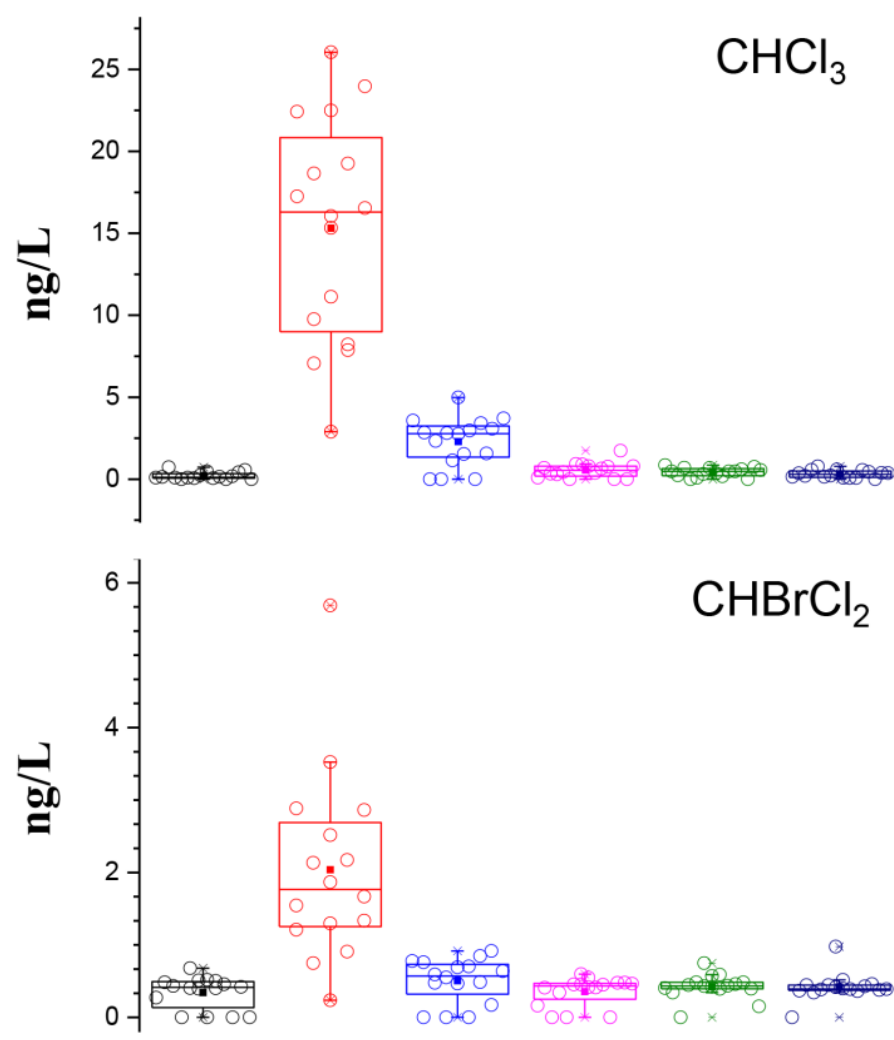

$\mathrm{CHBrCl}_{2}$

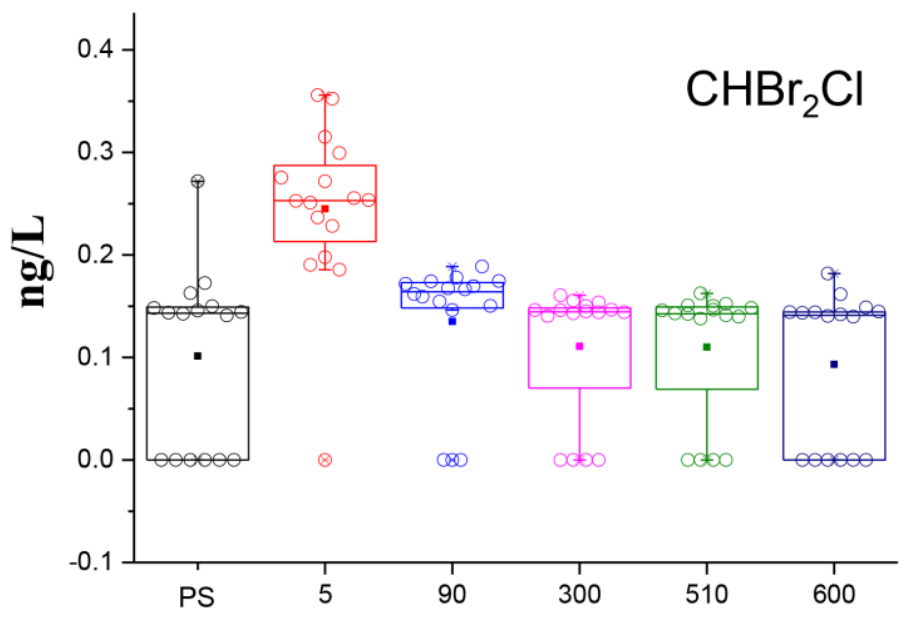

Time post-swimming ( $\min )$

Figure 4. Box and whisker plots to show estimated exhaled breath concentrations for chloroform $\left(\mathrm{CHCl}_{3} ;\right.$ top $)$ bromodichloromethane $\left(\mathrm{CHBrCl}_{2} ;\right.$ middle $)$ and dibromochloromethane $\left(\mathrm{CHBr}_{2} \mathrm{Cl}\right.$; bottom) in 16 participant exhaled breath $\mathrm{VOC}$ samples taken over 600 min post-swimming. Boxes refer to median and interquartile range and whiskers as $1 \%$ and $99 \%$ percentiles. Although there is approximately an order of magnitude difference in maximum concentration between each compound the washout trends follow the same pattern.

Note: PS indicates the relative exhaled concentrations of chloroform present in the preswimming sample. 


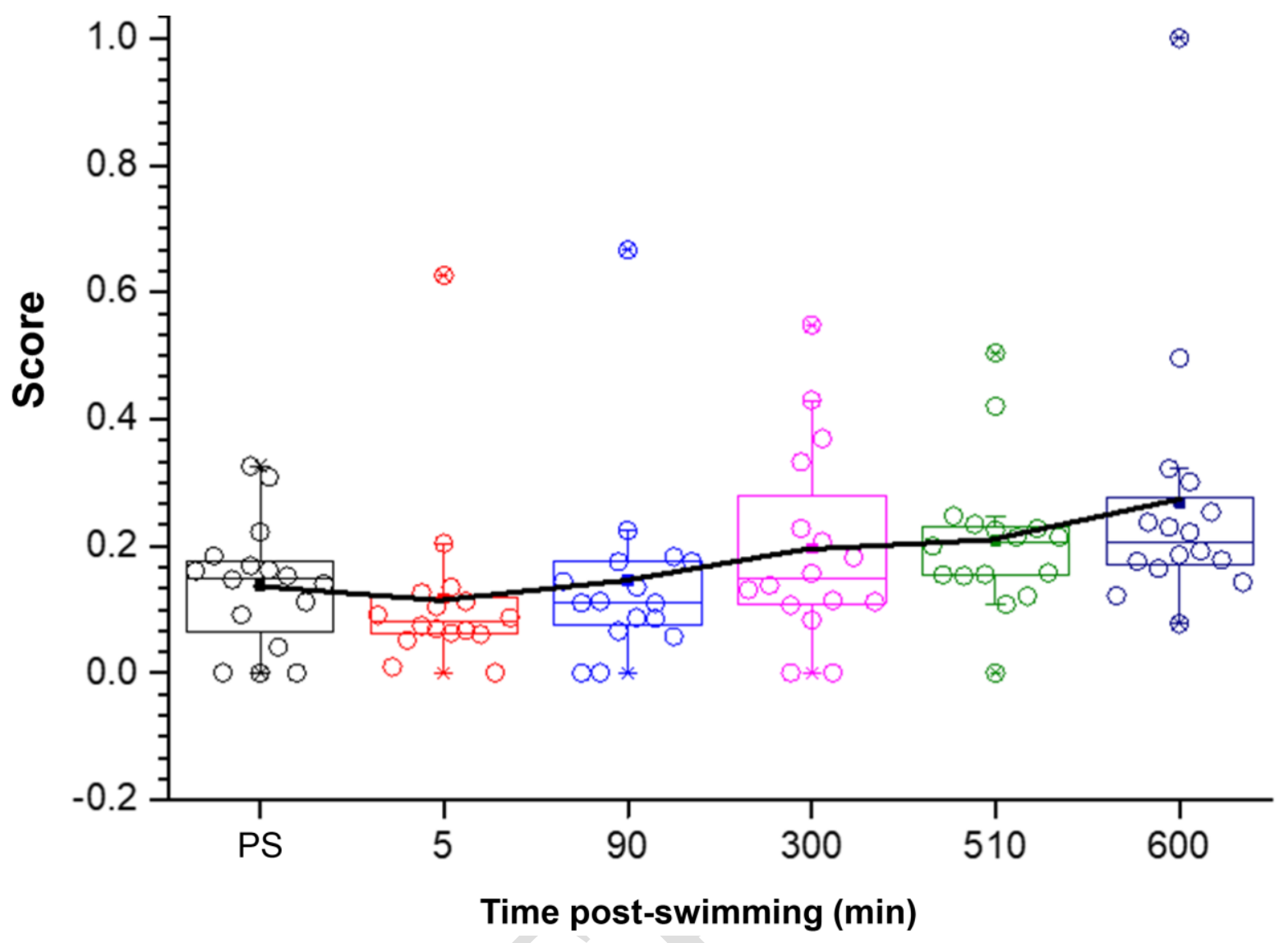

Figure 5. Normalized Euclidian score for benzofuran-2-carboxaldehyde and (5E)-6,10dimethylundec-5,9-dien-2-one (also known as geranylacetone) indicating an observed trend of increasing abundance of these compounds in exhaled breath following cessation of swimming.

Note: PS indicates the relative exhaled concentrations of chloroform present in the preswimming sample. 


\section{SUPPORTING INFORMATION}

Evidence for alternative exhaled elimination profiles of disinfection by-products and potential markers of airway responses to swimming in a chlorinated pool environment

Liam M Heaney ${ }^{1}$, Shuo Kang ${ }^{2}$, Matthew A Turner ${ }^{2}$, Martin R Lindley ${ }^{1,3}$, CL Paul Thomas ${ }^{2}$

${ }^{1}$ School of Sport, Exercise and Health Sciences, Loughborough University, Loughborough, LE11 3TU, UK

${ }^{2}$ Centre for Analytical Science, Department of Chemistry, Loughborough University, Loughborough, LE11 3TU, UK

${ }^{3}$ Translational Chemical Biology Research Group, Loughborough University, Loughborough, LE11 3TU, UK 
Table S1. Thermal desorption, gas chromatography and mass spectrometry conditions for the analysis of exhaled breath volatile organic compound samples.

\begin{tabular}{|c|c|c|}
\hline Parameter & Level & Units \\
\hline \multicolumn{3}{|c|}{ Thermal desorption conditions (Markes Unity 1) } \\
\hline $1^{\circ}$ Desorption temperature & 300 & ${ }^{\circ} \mathrm{C}$ \\
\hline $1^{\circ}$ Desorption time & 5 & $\min$ \\
\hline \multicolumn{3}{|l|}{ Cold trap: General purpose hydrophobic } \\
\hline Cold-trap temperature & -10 & ${ }^{\circ} \mathrm{C}$ \\
\hline Cold-trap desorption temperature & 300 & ${ }^{\circ} \mathrm{C}$ \\
\hline Cold-trap desorption time & 5 & $\min$ \\
\hline Transfer line temperature & 80 & ${ }^{\circ} \mathrm{C}$ \\
\hline \multicolumn{3}{|l|}{ Gas chromatograph (Varian 3800) } \\
\hline \multicolumn{3}{|c|}{ Column: DB-5ms $60 \mathrm{~m}$ long x $0.25 \mathrm{~mm}$ i.d. $\mathrm{x} 0.25 \mu \mathrm{m}$ film thickness } \\
\hline Column temperature initial & 40 & ${ }^{\circ} \mathrm{C}$ \\
\hline Hold time at initial column temperature & 0 & $\min$ \\
\hline Column temperature ramp & 5 & ${ }^{\circ} \mathrm{C} / \mathrm{min}$ \\
\hline Final column temperature & 300 & ${ }^{\circ} \mathrm{C}$ \\
\hline Hold time at final column temperature & 8 & Min \\
\hline \multicolumn{3}{|c|}{ Mass spectrometer conditions (Varian 4000) } \\
\hline Trap temperature & 150 & ${ }^{\circ} \mathrm{C}$ \\
\hline Manifold temperature & 50 & ${ }^{\circ} \mathrm{C}$ \\
\hline Transfer line temperature & 300 & ${ }^{\circ} \mathrm{C}$ \\
\hline$m / z$ scan frequency & 2 & $\mathrm{~Hz}$ \\
\hline$m / z$ scan range & 40 to 450 & $m / z$ \\
\hline
\end{tabular}


Table S2. Anthropometric characteristics of all participants categorized by the identification of an expected or delayed washout of swimming pool disinfection by-products.

\begin{tabular}{|c|c|c|c|c|c|c|c|}
\hline \multicolumn{8}{|l|}{$\begin{array}{l}\text { Expected } \\
\text { Washout }\end{array}$} \\
\hline Participant ID & $\begin{array}{l}\text { Age } \\
(y r s)\end{array}$ & $\begin{array}{c}\text { Mass } \\
(\mathrm{kg})\end{array}$ & $\begin{array}{l}\text { Height } \\
(\mathrm{cm})\end{array}$ & $\begin{array}{c}\text { BMI } \\
\left(\mathrm{kg} / \mathrm{m}^{2}\right)\end{array}$ & $\begin{array}{l}\text { BSA } \\
\left(\mathrm{m}^{2}\right)\end{array}$ & $\begin{array}{c}\text { Distance } \\
\text { Swam (m) }\end{array}$ & $\begin{array}{c}\text { Swimming } \\
\text { pool load }\end{array}$ \\
\hline Participant 01 & 25 & 65.8 & 184 & 19.4 & 1.83 & 1250 & 17 \\
\hline Participant 03 & 24 & 65.4 & 167 & 23.4 & 1.74 & 800 & 5 \\
\hline Participant 04 & 26 & 72.2 & 182 & 21.8 & 1.91 & 1625 & 5 \\
\hline Participant 05 & 24 & 69.3 & 165 & 25.4 & 1.78 & 850 & 13 \\
\hline Participant 06 & 24 & 76.4 & 179 & 24.0 & 1.95 & 1000 & 8 \\
\hline Participant 08 & 27 & 69.8 & 168 & 24.7 & 1.81 & 1550 & 7 \\
\hline Participant 09 & 26 & 86.2 & 175 & 28.3 & 2.04 & 1425 & 3 \\
\hline Participant 11 & 31 & 88.5 & 186 & 25.6 & 2.14 & 1375 & 5 \\
\hline Participant 12 & 25 & 81.1 & 186 & 23.4 & 2.05 & 1100 & 5 \\
\hline Participant 13 & 25 & 79.5 & 175 & 26.0 & 1.97 & 975 & 4 \\
\hline Participant 14 & 23 & 65.2 & 177 & 20.8 & 1.79 & 1450 & 3 \\
\hline Participant 15 & 23 & 103.7 & 180 & 32.0 & 2.28 & 1000 & 3 \\
\hline Participant 16 & 26 & 95.9 & 187 & 27.4 & 2.23 & 1175 & 5 \\
\hline Participant 17 & 21 & 80.3 & 181 & 24.6 & 2.01 & 1200 & 8 \\
\hline Participant 18 & 25 & 72.1 & 178 & 22.8 & 1.89 & 775 & 7 \\
\hline Participant 19 & 21 & 93.2 & 177 & 29.7 & 2.14 & 900 & 12 \\
\hline Mean values & 25 & 79.0 & 178 & 25.0 & 1.97 & 1153 & 7 \\
\hline \multicolumn{8}{|l|}{ Delayed } \\
\hline Participant 02 & 24 & 68.8 & 170 & 23.8 & 1.80 & 1550 & 5 \\
\hline Participant 07 & 23 & 69.1 & 170 & 24.0 & 1.80 & 1250 & 4 \\
\hline Participant 10 & 24 & 74.4 & 177 & 23.7 & 1.91 & 1450 & 10 \\
\hline Mean values & 24 & 70.7 & 172 & 23.9 & 1.84 & 1417 & 6 \\
\hline
\end{tabular}

Note: swimming pool load refers to the number of other swimming pool users at the time of the exercise session. 

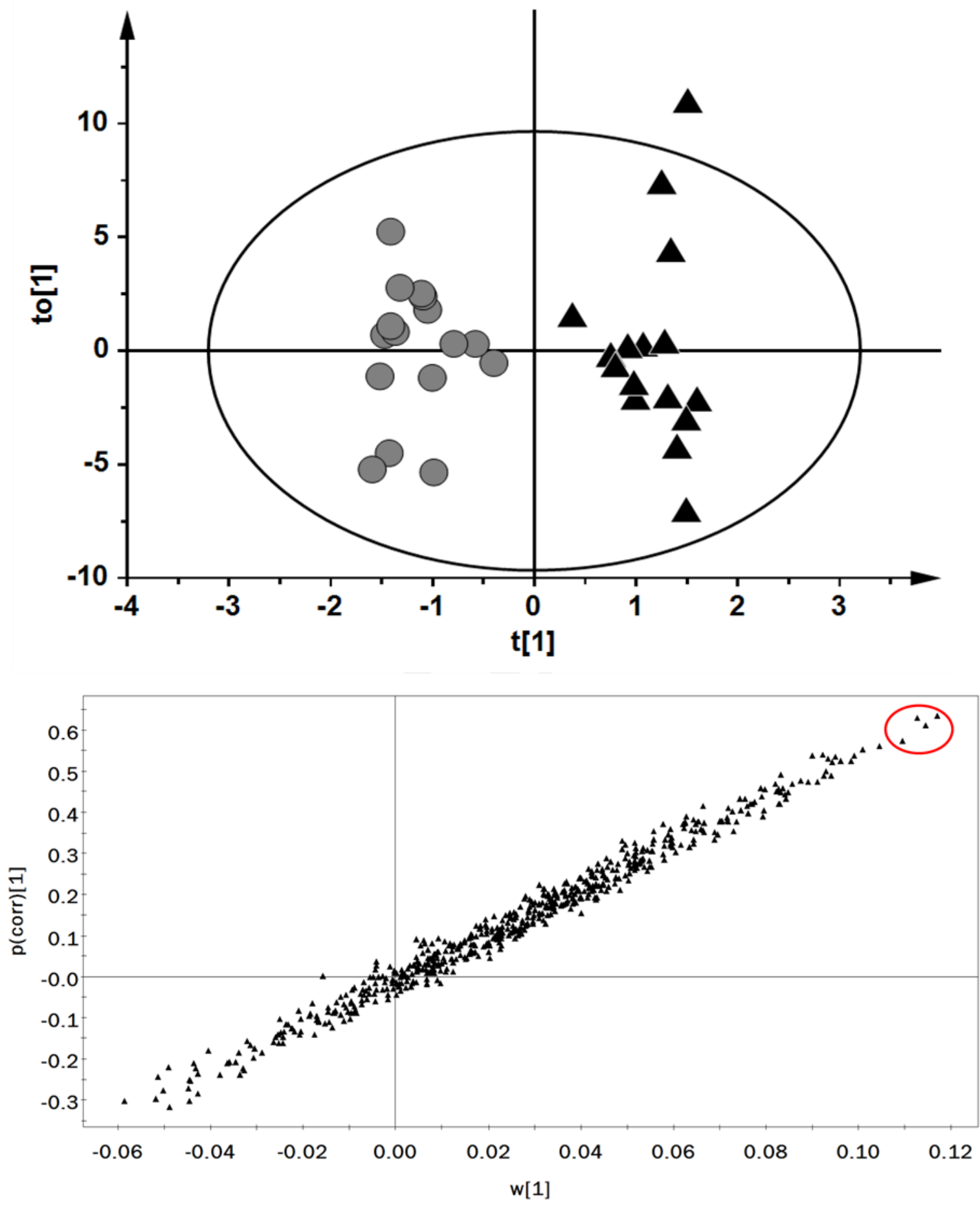

Figure S1. OPLS-DA scores plot (top) and s-plot (bottom) indicating four upregulated VOCs that were investigated further as markers of swimming. From this set two compounds benzofuran-2-carboxaldehyde and (5E)-6,10-dimethylundec-5,9-dien-2-one (also known as geranylacetone) were identified as up-regulated endogenous discriminators.

Note: grey circles represent pre-swimming exhaled breath samples and black triangles $600 \mathrm{~min}$ post-swimming. 